\title{
Questioning as an Effective Tool to Enhance Students' Interaction in the English Classroom
}

DOI: $10.46932 / \mathrm{sfjdv2n2-185}$

Received in: March 1st, 2021

Accepted in: May 30th, 2021

Yola Indaura Chica Cárdenas

Magister in English Language and Applied Linguistics - Universidad de Cuenca, Ecuador Master in Curriculum and Instruction ESL - Kansas State University

Current Institution: Universidad de Cuenca

Full personal address: Beethoven y Vivaldi

01026, Cuenca, Ecuador

Email: yola.chica@ucuenca.edu.ec

\begin{abstract}
The educational process requires teachers to use a variety of strategies to support students in the process of learning, and one of the most widely used strategies is questioning. Studies carried out by different researchers have demonstrated the positive effects of proper questioning in the learning process; on the other hand, it is worth mentioning that most teachers customarily use questioning in their classes, even though not all of them use it correctly. For this reason, the aim of this paper is to raise teachers' awareness on the effectiveness of appropriately using questioning in the classroom. The information presented in this paper has been collected through a systematic Literature Review of a variety of sources related to this tool used in education. This Literature Review has been organized chronologically by publication and, in some cases, by themes. In relation to results, the majority of researches recognizes and emphasizes the positive effects of adequately applying questioning in the classroom. This tool enhances interaction and, consequently, promotes the development of students' skills, to make the learning process more effective.
\end{abstract}

Key words: questioning, interaction, students’'skills

\section{INTRODUCTION}

The educational process requires the teacher to consider the student as the center of the instructional process. This student-centered approach encompasses shifting the focus of instruction from the teacher to the student. That means moving from a traditional perspective of teaching to one in which students are able to construct knowledge by themselves, with their teacher's support. In this construction of knowledge, students should be the ones that interact, talk, and debate or discuss in the classroom most of the time; however, it does not happen in real life. Teachers are the ones who are always talking during the instructional process (Wangru, 2016; Tamas \& Wang, 2017), and one of the features of teachers' talk is to ask questions.

Iksan and Daniel (2015) state that teachers can ask up to 80 questions in a one-hour teaching session. According to Tamas and Wang (2017), teachers ask 93\% of the questions posed in class. That means that, according to them, only $7 \%$ of the questions are asked by students. If this percentage of 
students ${ }^{\prime}$ talk is considered, it can be inferred that students are not yet the center of the educational process and that there is no real interaction in the classroom.

Classroom interaction involves teacher-student interaction, student-student interaction, group discussion and all types of class participation (Al-Zahrani \& Al-Bargi, 2017). Teachers must be aware that any kind of interaction influences the whole teaching and learning process, that the increase of interaction makes communication improve, and that the improvement of communication involves the enhancement of students' ${ }^{\prime}$ cognitive, social and thinking skills. That is, they must realize that learning emerges from social interaction (Harvey \& Light, 2015), and that one of the means for enhancing interaction in the classroom is to use questioning efficiently. For helping teachers achieve this goal, this paper presents some background information about questioning, emphasizes its importance in the learning process, provides some important guidelines for using it properly, and ends setting up some conclusions.

\section{QUESTIONING}

Most methods of classroom teaching are based on questioning (Gall, 1970). "Questioning strategies are the ways which are used to ask something to the students in gaining a purpose in teaching" (Rahman, \& Mahmud, 2016, p. 107). Davoudi and Sadeghi (2015) consider questioning a teaching and learning strategy. According to Fries-Gather (2008), this questioning strategy is one of the most important dimensions of teaching and learning.

Questioning, that is based on asking questions, has been considered as a technique (Harvey \& Goudvis, 2000; Al-Zahrani \& Al-Bargi, 2017), as a strategy (Harvey \& Goudvis, 2000; Fries-Gather, 2008, Davoudi \& Sadeghi, 2015), or as a teaching tool (Tofade, 2013; Elsner \& Haines, 2013). The fact of assigning different names to refer to this tool is not as important as the fact of recognizing the positive influence it has had on the learning process when properly applied.

\section{TYPES OF QUESTIONS}

A question can be considered as a statement that has a formal interrogative structure, or it could involve a command or any kind of expression that intends to get information; that is, a sentence, a phrase, or a gesture that seeks information through a reply (Linch, 1991, as quoted in Rahman \& Mahmud, 2016). Questions are not an end in themselves; they are means to an end (Gall, 1970).

Questions can be categorized into two groups. The first group includes all types of questions whose main goal is to confirm or corroborate information or to check for understanding. Teachers already know the answers to these questions. Another characteristic of this group of questions is that they are lowlevel questions that do not promote interaction; consequently, they do not enhance students' thinking 
skills. These questions are known as recalling questions (Gall, 1970), display questions (Wangru, 2016; Al-Zahrani \& Al-Bargi, 2017, or classroom management questions (Iksan \& Daniel, 2015; Tamas \& Wang, 2017). On the other hand, the second group includes questions whose main goal is to promote interaction and to enhance students' thinking skills (Wangru, 2016). Teachers do not know the answers to these high-level questions, which are also known as referential questions (Wangru, 2016; Al-Zahrani \& Al-Bargi, 2017) or divergent questions (Al-Zahrani \& Al-Bargi, 2017).

Tamas and Wang (2017) asseverate that the way in which teachers ask questions and the type of questions they ask in the classroom may have an impact on learning. They affirm that, when teachers use low-level or memory-recall questions, they do not elicit students' higher-order thinking skills, so there is not a co-construction of knowledge because students simply rely on the information provided by the teacher. In contrast, high-cognitive level questions are open, divergent, and dialectical and they allow a wide range of answers that encourages learners to think critically, imaginatively, and creatively. Certainly, researchers state that both types of questions are necessary in the classroom; however, they advise teachers to emphasize the ones that promote interaction and the development of students' ${ }^{\prime}$ thinking and communicative skills.

\section{THE IMPORTANCE OF QUESTIONING IN THE CLASSROOM}

The influence questioning has in the classroom has been investigated by many researchers who have demonstrated its relevance when properly applied. Davoudi and Sadeghi (2015) conducted a study in which they did a deep review of researches dealing with questioning carried out from 1974 to 2014. They analyzed more than 100 studies and the findings revealed that both teacher and student questioning have a very important role in the educational process. Actually, teachers use questioning every day for many purposes, such as to enhance classroom interaction (Harvey \& Light, 2015; Rahman \& Mahud, 2016; Wangru, 2016; Al-Zahrani \& Al-Bargi, 2017), to assess students' performance (FriesGather, 2008; Rahman \& Mahud, 2016), to facilitate critical thinking, writing ability, reading comprehension, subject matter learning, and metacognitive skills (Davoudi \& Sadeghi, 2015). All the purposes of proper questioning improve the quality of classroom teaching (Iksan \& Daniel, 2015; Rahman \& Mahmud, 2016) and enhance students' communicative competence and overall abilities in second language learning.

In relation to interaction, Al-Zahrani and Al-Bargi (2017) affirm that teachers use questions in the EFL classroom to involve students in discussions and to promote interaction. They also assert that teachers have to ask high-cognition level questions since these are the ones that promote higher levels of interaction. In addition, Wangru (2016) affirms that, when questioning is effective, it increases the 
quality and quantity of interaction in the classroom. In the same vein, Rahman and Mahud (2016) affirm that proper questioning makes interaction and communication between teacher and students more valuable.

Regarding the possibility of using questioning for assessing students' performance, Rahman and Mahud (2016) state that the proper use of questioning promotes interaction that allows teachers to obtain output from students and to assess how the process of instruction is going. Similarly, Fries-Gather (2008) affirms that questioning gives tutors the chance to find out what students know and understand, and it also allows students to look for clarification and help. It means that, through questioning, teachers are able to know what students know and what they do not know to continue with teaching or to provide immediate feedback.

Effective questioning is also relevant for improving the quality of teaching (Iksan \& Daniel, 2015; Rahman \& Mahmud, 2016). Admittedly, when the teacher asks questions in a proper way, students are able to answer them. As a consequence of this interaction, the teacher can get output from students, realize how students are doing during the instructional process, and help them overcome their difficulties in an effective way. In addition, students are motivated to participate; they get involved in the learning process (Harvey, 2015), and this process becomes meaningful to them. To achieve this goal, Iksan and Daniel (2015) assert that teachers should use a variety of questions during the teaching and learning process. They affirm that both content and management questions are necessary in the instructional process, and that questioning should be improved. Rahman and Mahmud (2016) state that if a teacher teaches without questioning, it may be due to the fact that the teacher is in a hurry, does not understand the material well, does not care about the students' performance, or is lazy. According to them, the fact of not asking questions in the classroom causes negative effects and affects the students' performance and teaching quality.

In addition, proper questioning in teaching is relevant to enhance students' critical thinking (Jueneman, 2004; Eggen \& Kauchak, 2006; Snyder \& Snyder, 2008; Ruiz-Primo, 2011; Iksan and Daniel, 2015; Wangru, 2016). Davoudi and Sadeghi (2015) affirm that high-level questions enhance the development of students' critical thinking abilities. They also state that questioning facilitates critical thinking, writing ability, reading comprehension, subject matter learning, metacognitive skills, and the scaffolding learning process. More effective classroom questioning can encourage all students to think at higher cognitive levels (Wangru, 2016). Teachers using open-ended questions promote students ${ }^{\prime}$ higher order thinking skills that help them create their own meanings and enhance knowledge construction; that is, questions have a direct influence on the thinking and learning habits of students and help 
them create their own meanings, which contributes to the construction of knowledge (Tamas and Wang, 2017).

Al-Zahrani and Al-Bargi (2017) asseverate that high-proficiency level students ask and answer questions that demand reasons and justifications. Those are questions that require students to express their thoughts, opinions, or viewpoints. Also, these questions could lead from teacher-controlled interaction to a conversational pattern in which students are the ones that guide the discussion and become the center of the educational process. Davoudi and Sadeghi (2015) affirm that good questions can help students improve their linguistic competence and strategic questioning can stimulate students' imagination and motivate them to look for new knowledge.

As it has been stated by many researchers, proper questioning positively influences the educational process. In relation to teaching English as a Foreign Language, this tool enhances students' communicative competence and overall abilities in language learning. In fact, if interaction in the classroom is enhanced through questioning, the result is that students' communicative competence is also enhanced. As a consequence of the enhancement of students' communicative competence, other abilities in the learning of the target language are improved as well.

\section{PROPER QUESTIONING}

If teachers ask questions at all times during the educational process, they need to be aware of the importance this strategy has for enhancing the learning process, and they should also know how to ask questions properly. Al-Zahrani and Al-Bargi (2017) state that the first step teachers have to take to help their students in the learning process is to be aware of the relevance questioning has in the classroom. In addition, Gall (1970) affirms that an improvement of teachers' questioning practices is necessary. That means teachers have to know some questioning strategies (Tofade, Elsner, \& Haines, 2013). Even more, Gall (1970), Tamas and Wang (2017) affirm that teachers need professional development to learn how to use questioning properly for implementing effective questioning strategies in the classroom (Gall, 1970).

Indeed, researchers have demonstrated the relevance questioning has in the classroom. However, many teachers are not aware of the importance this tool has for achieving many purposes that benefit students in the instructional process. In fact, they customarily ask questions without reflecting on their usefulness when they are properly posed. Considering the reality of our educational context, it is not probably possible to organize training seminars for teachers with the goal of helping them become skilled questioners; however, some guidelines that can make them reflect on their pedagogical practices when asking questions and guide them to set them up are given here. Extensive research has proved these to be effective. 


\section{WAITING TIME}

When a teacher poses a question to a student and the student does not answer immediately, what the teacher does is to redirect the question to another student, and, if this student does not answer either, the teacher again redirects the question to a third student. This pedagogical practice is not appropriate. Waiting time is a period of silence, both before (Eggen \& Kauchak, 2006) and after a student responds (Eggen \& Kauchak, 2006; Wangru, 2016). When the teacher is patient and waits, the level of students' anxiety decreases, they give longer and better responses, and voluntary participation increases (Eggen \& Kauchak, 2006); that is, students feel confident and do not fear taking risks when trying to answer the question posed by the teacher.

According to the results of the research carried out by Wangru (2016), students expect their teacher to wait for a period of 3 to 5 seconds after a question is posed, so they can organize their answers. He also advices teachers that, if after 15 seconds nobody answers a question, they should leave it unanswered and tell students to think about it after class. They can ask the same question again at the beginning of the next class. For him, the post-response waiting time is significant and advices teachers, when asking a question, to wait for the students to finish their speaking totally and not to push them to finish it.

\section{EQUITABLE DISTRIBUTION}

It means that the teacher must ask questions to all the students in the class and not only to the ones that are seated in the front or the ones that are able to answer the questions very quickly. Wangru (2016) affirms that a good strategy is to ask for volunteers to answer questions; this strategy cultivates students' initiative; however, sometimes the same students volunteer all the time, and they monopolize the class. Then teachers should do equitable distribution of questions and involve all the class by thanking the students who are volunteering all the time and calling upon non-volunteers in a friendly, non-threatening manner. It is also important to emphasize that, if the teacher asks questions to all the students, they will feel the teacher is fair and will be also predisposed to answer them. They will be mentally prepared to participate.

\section{PROMPTING}

Prompting refers to the fact that, if the teacher poses a question and the student's answer is "I do not know" or if he remains silent or gives a weak answer, the teacher must give some hints to guide and encourage him/her to provide an answer (Eggen \& Kauchak, 2006; Wangru, 2016). Prompting can 
involve other strategies, such as paraphrasing, giving examples, decomposition, simplification, prolonging waiting time, and description (Eggen \& Kauchak, 2006).

\section{PROBING}

Asking just one question does not provoke enough interaction. Probing refers to a series of questions or comments addressed to one student that is designed to elicit a more nearly complete or proper answer. Probing makes students sustain their answers and think at higher levels (Eggen \& Kauchak, 2006). Questions that help achieve this goal are the "why" questions (Wangru, 2016).

\section{REPEATING}

Repeating means that, when the teacher asks a question and nobody answers, the teacher has to repeat it for some reasons, like for example to ensure everybody has listened to it, to check if everybody has understood it, to encourage students to give their opinions, to break silence and activate the class, or to leave more time for students to think (Eggen \& Kauchak, 2006). It is a good idea to walk around the class when repeating the question.

\section{REDIRECTING}

Redirecting means to ask the same question to several students. It is also known as shifted interaction. If a student responds incompletely or incorrectly, the teacher has to prompt that student first. If the prompting is not productive, the teacher can redirect the question to a second or to a third student. This strategy can be also used when the teacher wants another student to illustrate more or to provide more examples (Eggen \& Kauchak, 2006).

\section{PLANNING QUESTIONS}

Wangru (2016), Al-Zahrani, and Al-Bargi (2017) advice teachers to plan the questions they want to ask in each lesson. That means that, when planning, teachers should prepare the questions students have to answer based on content or according to the purpose they are trying to accomplish. These questions should be challenging questions that make students reflect and think critically.

\section{TEXT CONTENT AND STUDENTS' LEVEL}

Questions must be asked considering the content students are learning and the level of language they have (Wangru, 2016; Al-Zahrani1 \& Al-Bargi, 2017). Teachers have to be aware that content 
questions should occur in a process, from simplest to most complex. If a student is able to answer a simple question, the teacher should continue with the more complex ones to ensure that this student has understood and can go ahead. On the contrary, if the teacher asks students complex questions without having them answer the previous, simple ones, there will not be a basis for knowledge construction.

\section{FEEDBACK AND ERROR CORRECTION}

After a student answers a question, it is more productive if the teacher provides feedback by commenting on or explaining students' responses rather than simply answering 'yes,' 'good,' 'thank you,' etc. (Wangru, 2016). Besides, Wangru (2016) asserts that it is a good idea that teachers provide positive feedback to underachievers when they give correct answers to questions and provide proper feedback to the ones who do not answer the questions correctly. Similarly, teachers should avoid giving students explicit negative feedback because students will feel disappointed and they would not dare to participate again. If the students' answers are wrong, teachers should not interrupt their answers and correct them. It will withdraw their initiative. If it is an important mistake, the teacher can give implicit negative feedback, correct, and explain it in detail after the student has finished answering the question. If it is a minor mistake, the teacher can let it go if it does not hinder communication. In this way, teachers can provide feedback orally, but they can also provide feedback by making gestures, such as nodding or smiling. In addition, teachers must be aware that positive feedback provides students with a comfortable classroom atmosphere in which they feel confident and relaxed and do not fear making mistakes (Wangru, 2016).

\section{CONCLUSIONS}

Education tries to ensure that students be the center of the educational process and expects them to construct knowledge by themselves in a comfortable classroom environment with their teacher's support. The achievement of this goal is strongly related to questioning. Awareness of its importance and the benefits this tool provides students when properly used will help achieve it.

Extensive research has demonstrated the usefulness of questioning when properly used. It influences positively the learning process and presupposes that students talk, ask questions, and interact most of the time. This fact does not happen in reality. Paul and Elder (2007) affirm that students need direct instruction on how to construct and ask deep questions. We would dare to say that teachers also need to know more about this tool, its importance, and how to apply it efficiently in the classroom. Teachers do not have to use questioning as a daily routine without reflecting on its relevance. They must use it properly as an effective tool that promotes classroom interaction, enhances students' communicative competence, and makes the learning process more efficient. 
In sum, we must be aware of the relevance of proper questioning in the classroom and of the strong connection it has with the increase of interaction, the improvement of students communicative competence, and the improvement of their cognitive, social, and thinking skills. By doing this, the instructional process will undoubtedly be better and more effective. 


\section{REFERENCES}

Al-Zahrani, M. Y., \& Al-Bargi, A. (2017). The Impact of Teacher Questioning on Creating Interaction in EFL: A Discourse Analysis. English Language Teaching, 10(6), 135. doi:10.5539/elt.v10n6p135

Davoudi, M., \& Sadeghi, N. A. (2015). A Systematic Review of Research on Questioning as a High-level Cognitive Strategy. English Language Teaching, 8(10). doi:10.5539/elt.v8n10p76

Eggen, P. D., Kauchak, D. P. (2006).Strategies and Models for Teachers: Teaching Content and Thinking Skills. Boston: Pearson Education, Inc.

Fries-Gaither, J. (2008). Questioning Techniques: Research-Based Strategies for Teachers —. Retrieved from http://beyondpenguins.ehe.osu.edu/issue/energy-and-the-polar-environment/questioningtechniques-research-based-strategies-for-teachers

Gall, M. D. (1970). The Use of Questions in Teaching. Review of Educational Research,40(5), 707. doi:10.2307/1169463

Harvey, S., \& Goudvis, A. (2000). Strategies that work: Teaching comprehension to enhance understanding. York, Me.: Stenhouse.

Harvey, S., \& Light, R. L. (2015). Questioning for learning in game-based approaches to teaching and coaching. Asia-Pacific Journal of Health, Sport and Physical Education, 6(2), 175-190. doi:10.1080/18377122.2015.1051268

Iksan, Z. H., \& Daniel, E. (2015). Emerging Model of Questioning through the Process of Teaching and Learning Electrochemistry. International Education Studies, 8(10). doi:10.5539/ies.v8n10p137

Juenemann, P. (2004). "Let's Talk": Discussion in a Biology Classroom: An Action Research Project? In Gay, L. R., Mills, G. E., Airasian, P. (Eds.), Educational research: Competencies for Analysis and Applications (521-529). New Jersey: Pearson education, Inc.

Paul, R., \& Elder, L. (2007). Critical thinking: The art of socratic questioning.Journal of Developmental Education, 31(1), 36-37. from https://search.proquest.com/docview/228487383?accountid=36749

Rahman, Q., \& Mahmud, M. (2016). English Teacher's Questioning Strategies in EFL Classroom at SMAN 1 Bontomarannu. ELT Worlwide, 3(1), ISSN 23033037 E-ISSN 25032291

Ruiz-Primo, M. A. (2011). Informal formative assessment: The role of instructional dialogues in assessing students' learning. Studies in Educational Evaluation, 37(1), 15-24. doi:10.1016/j.stueduc.2011.04.003

Ruiz-Primo, M. A., \& Furtak, E. M. (2006). Informal formative assessment and scientific inquiry: Exploring teachers' practices and student learning. Educational Assessment, 11(3-4), 237-263. doi:10.1080/10627197.2006.9652991

Snyder, L. G., \& Snyder, M. J. (2008). Teaching critical thinking and problem solving skills. Delta Pi Epsilon Journal, 50(2), 90-99. Retrieved from http://search.proquest.com.er.lib.kstate.edu/docview/195581754?accountid=11789 
Tamas, K., \& Wang, A. (2017). Investigating Teacher Questions within the Framework of Knowledge Building Pedagogy.Journal of International Social Studies, 7(1), 55-69. Recovered from: https://files.eric.ed.gov/fulltext/EJ1151080.pdf

Tofade, T., Elsner, J., \& Haines, S. T. (2013). Best Practice Strategies for Effective Use of Questions as a Teaching Tool.American Journal of Pharmaceutical Education,77(7), 155. http://doi.org/10.5688/ajpe777155

Wangru, C. (2016). The Research on Strategies of College English Teachers Classroom Questioning. International Education Studies, 9(8), 144. doi:10.5539/ies.v9n8p144 